\title{
Effects of Non-Indigenous \\ Australian Human Resource \\ Managers' Gender and Attitudes \\ and Applicants' Ethnicity and \\ Gender on Resumé Evaluations
}

\author{
Lauren Hughes and Graham R. Davidson \\ University of the Sunshine Coast, Australia
}

\begin{abstract}
In this web-based survey, 60 non-Indigenous Australian human resource (HR) professionals reviewed four fictitious job resumés for an Indigenous male, Indigenous female, non-Indigenous male and nonIndigenous female. Participants rated the resumés against five key selection criteria and then ranked them in terms of suitability for a HR position, team fit (TF) with participants' current HR team, and suitability for a customer service (CS) position. Finally, participants completed a modified Attitude toward Indigenous Australians scale. Although participants' gender and attitudes and applicants' gender and ethnicity did not have an effect on resumé ratings, rank differences for the HR position and TF for the whole sample were significantly different, with the non-Indigenous male applicant being preferred to the Indigenous male and female applicants. Participants holding a negative attitude toward Indigenous people consistently ranked the non-Indigenous male applicant more favourably than the Indigenous male and female applicants and the non-Indigenous female applicant more favourably than the Indigenous male applicant. Female participants ranked the non-Indigenous male applicant more favourably than the Indigenous male and female applicants for the HR position and TF. Implications for Indigenous Australian employment disadvantage are examined with reference to social identity and contemporary racism theories.
\end{abstract}

Keywords: Australia, Indigenous, ethnicity, gender, attitudes, job selection

Best employment practices include selection of job applicants on merit; and national and state antidiscrimination laws make discriminatory selection practices illegal (e.g., Australian Government, 1975, 1984, 2004). This study investigated the influence of ethnicity and gender on evaluations of job applicants' resumés. It examined specifically whether non-Indigenous human resource (HR) professionals evaluate male and female Indigenous and non-Indigenous Australian job applicants' resumés differently. The term 'Indigenous' refers to persons who identify as Aboriginal, Torres Strait Islander, or both Aboriginal and Torres Strait Islander. The term 'non-Indigenous' refers to all other Australians.

\section{Indigenous Australian Unemployment}

Australian employment statistics paint a gloomy picture of Indigenous employment. Indigenous Australians (14\%) are approximately three times more likely to be unemployed than Australians overall (4.4\%). Gender differences emerge, with Indigenous females (14.7\%) being more likely to be unemployed than Indigenous males (13.5\%; Australian Bureau of Statistics [ABS], 2007, 2008); see also Podsiadlowski and Ward (2010) for European Union, Canadian, and New Zealand data on comparative employment rates of ethnic majority and ethnic minority residents.

These employment statistics suggest that Indigenous people experience extreme disadvantage when job 
hunting. The situation is very concerning as the benefits of employment, and consequences of undesired unemployment are well documented (Feather \& O'Brien, 1986; Stokes, 1991; Warr, 1978; Winefield et al., 2002). The negative consequences of unemployment are alleviated allegedly by the extent to which employment is considered personally to be of value. Winefield et al. (2002) maintained that 'high rates of unemployment in Aboriginal communities are regularly cited as negative social indicators, yet these reflect ... a cultural value system that is simply very different' (p. 2). A similar perspective was offered by some participants in Hoban's (2002) roundtable discussion with members of the Koori (Indigenous) community in the Goulburn Valley area of Victoria, during which one Koori participant stated that caring for family is more important than securing and retaining paid employment.

However, claims that Indigenous Australians do not want to work were strongly refuted by Davidson (1984) and Tickner (1994) who disputed opinions that Indigenous Australians lack the motivation required to obtain work or assign little value to being employed. Davidson suggested that discriminatory practices in the workplace contribute to the high rate of Indigenous unemployment. Other focus group data suggest that some non-Indigenous Australians erroneously assume that: very few Indigenous Australians are employed; those who have jobs keep them only for short periods; few hold responsible, skilled positions; and they are lazy, unreliable, lacking persistence and irresponsible (Donovan \& Leivers, 1993). Such false beliefs have been found to be strongly related to prejudice against Indigenous Australians, which is alarmingly common among nonIndigenous Australians, with more than one third to one half of the latter showing signs of prejudice (Pedersen, Beven, Walker, \& Griffiths, 2004; Pedersen, Dudgeon, Watt, \& Griffiths, 2006; Pedersen, Griffiths, Contos, Bishop, \& Walker, 2000; Pedersen \& Walker, 1997).

Research suggests that Indigenous people applying for a job may be much less likely than Caucasian Australians to obtain an initial job interview. Booth, Leigh, and Varganova (2009) conducted an employment discrimination audit in which they compared the call-back rates for Anglo-Australian, Indigenous Australian, Italian, Chinese, and Middle Eastern applicants. Results showed that, in order to obtain the same number of interviews as an Anglo-Australian applicant, an Italian person must submit $12 \%$ more applications, an Indigenous person must submit 35\% more applications, a Middle Eastern person must submit $64 \%$ more applications, and a Chinese person must submit $68 \%$ more applications. In the absence of evidence that the differential response rate relied on merit-based decision-making — resumés were fictitious and matched randomly with applicant ethnicity - it seems decision-makers' prejudicial attitudes about applicants' ethnicity influenced response rates.

\section{Effect of Decision-Makers' Attributes on Resumé Evaluation}

Evidence suggests that employment decision-makers' attributes and attitudes may influence their decisions about applicants' suitability for employment. Such evidence is consistent with decision-making models that rely on a social identity theory of behaviour (Tajfel \& Forgas, 2000; Tajfel \& Turner, 2004). Social identity and categorisation offer people a sense of social order and the opportunity to define themselves socially as a member of groups to which positive value is attached (Augoustinos, Tuffin, \& Sale, 1999; Blascovich, Wyer, Swart, \& Kibler, 1997; Gaertner \& Dovidio, 2005). For example, in the Australian context, Gomersall, Davidson, and Ho (2000) found that almost all $(97.7 \%)$ of non-Indigenous research participants indicated that their identity was influenced by membership of non-Indigenous Australian society. Approximately one third of participants considered Indigenous and non-Indigenous people to be distinctly different groups, and one fifth considered non-Indigenous Australians to be superior to Indigenous Australians. This clear in-group preference differs, for example, from the finding of Sibley, Liu, and Kahn (2008) that Pākehā (Caucasian) New Zealanders perceived both Pā kehā and Maori cultures to be important in defining New Zealand as a nation.

Predictions about employment decision-making based on social identity theory are consistent with observed differences in resumé evaluations related to social categorisation of ethnicity. In the majority of resumé research, judges drawn specifically from the ethnic majority demonstrated a preference for ethnic majority over minority applicants. Ethnic attitudes also have a role. Singer (1996) studied Pākehā New Zealand students' attitudes toward policies for increasing Maori employment participation that were either diversitydriven (redress of unfair discrimination) or preferential (promotion of reverse discrimination). Although Pākehā students overall were less supportive of preferential than of diversity-driven practices, students who held positive attitudes toward, and justice concerns for, Maori were more likely to support preferential employment practices and less likely to condone diversity-driven practices than students who held negative attitudes toward Maori. (See also Sibley and Liu (2004) on Pākehā students' support for resource sharing in the form of resourcespecific biculturalism.)

Decision-makers' gender has been shown to influence employment decision-making. A review by Gorman (2005) of the hiring records of U.S. law firms found that female recruiters were more likely than male recruiters to select female applicants for entry-level law positions. Levin, Rouwenhorst and Trisko (2005) found that $69.9 \%$ of respondents favoured and recommended appointment of an applicant of their own gender. Experience in recruitment and selection may also influ- 
ence decision-making (Dipboye et al., 1975; Gordon, Slade, \& Schmitt, 1986). Singer and Sewell (1989) found that decisions made by university student samples were not representative of those made by experienced recruiters.

\section{Effect of Applicant Attributes on Resumé Evaluations}

Applicant attributes such as gender (Dipboye, Fromkin, \& Wilback, 1975; Dipboye, Arvey, \& Terpstra, 1977; Marlowe, Schneider, \& Nelson, 1996; Singer, 1988), ethnicity (Dovidio \& Gaertner; 2000; Hosoda, Stone, \& Stone-Romero, 2003; Purkiss, Perrewé, Gillespie, Mayes, \& Ferris, 2006; Singer \& Eder, 1989), age (Gringart, Helmes, \& Speelman, 2008; Singer \& Sewell, 1989), body weight (Ding \& Stillman, 2005), pregnancy (Masser, Grass, \& Nesic, 2007), disability (Gouvier, SytsmaJordan, \& Mayville, 2003), and attractiveness (Dipboye et al., 1975; Dipboye et al.; 1977) have been shown to influence resumé evaluations and job selection. Ethnic majority applicants are more likely to be preferred than ethnic minority applicants. Male applicants are more likely to be preferred over female applicants. Such findings are reliable, irrespective of whether ethnicity and gender are stated directly or implied through inclusion of photographs or video depictions of gender and accent. They persist despite other applicant attributes. Furthermore, disadvantage for female and ethnic minority applicants is relatively greater for high cognitive demand (e.g., marketing) than low cognitive demand (e.g., mail-sorting) jobs. However, the interaction effects of gender, ethnicity and job type are contextually complex, leading Hosoda and colleagues (2003) to conclude that 'gender bias might differ as a function of a woman's race, especially for jobs that have high cognitive demand' (p. 164).

\section{Methodological Considerations in Resumé Evaluation Research}

Research into factors that influence resumé evaluation has relied increasingly on applicants' written resumés to avoid difficulties arising from matching applicants on factors such as physical attractiveness, dress, make-up, deportment and tone of voice (e.g., Dipboye et al., 1975; Dipboye et al., 1977; Marlowe et al., 1996). Furthermore, the majority of studies of gender and ethnicity effects on resumé evaluations have used participants' ratings as the dependent measure, although some studies have incorporated forced-choice ranking of resumés (Ding \& Stillman, 2005; Gouvier et al., 2003; Marlowe et al., 1996). Arvey (1979) suggested that forced ranks are more sensitive than ratings to subtle biases. Research findings support Arvey's position (Dipboye et al., 1975; Gouvier et al., 2003). The present study attempted to avoid these and other methodological pitfalls by using both ratings and ranking of written resumés specifically with $\mathrm{HR}$ recruitment professionals.

\section{The Present Study}

There is an absence of research in the Australian context into whether job applicants' ethnicity and gender and employers' attitudes and gender are crucial in determining employment rates for Indigenous Australians. The present study's primary aim, therefore, was to investigate: whether there are differences in how male and female non-Indigenous HR and recruitment professionals evaluate male and female Indigenous and non-Indigenous job applicants' resumés; and whether their evaluations are influenced by their attitudes toward Indigenous people. It also examined effect of job type by investigating differences in non-Indigenous HR professionals' evaluations of male and female Indigenous and non-Indigenous applications for a position within their own industry (a HR Coordinator position) or outside of their own industry (customer service $[\mathrm{CS}]$ position). HR professionals were asked to review and evaluate resumés of four fictitious applicants who differed according to ethnicity and gender, but who were otherwise similar in terms or their educational and employment experience. Taking into account overseas research into evaluation of ethnic majority and minority job applicants' resumés (Dovidio \& Gaertner, 2000; Hosoda et al., 2003; Purkiss et al., 2006; Singer \& Eder, 1989), and that at least a third of non-Indigenous people may be prejudiced against Indigenous people (Pedersen \& Walker, 1997; Pedersen et al., 2000; Pedersen et al., 2004; Pedersen et al., 2006), we predicted that non-Indigenous HR professionals would rate and rank non-Indigenous applicants' resumés more favourably than Indigenous Australian job applicants' resumés. Furthermore, based on social identity explanations of ethnic in-group versus outgroup favouritism, we predicted that non-Indigenous HR professionals who hold a negative attitude towards Indigenous Australians would be more likely than HR professionals who hold a positive attitude towards Indigenous Australians to rate and rank Indigenous applicants' resumés less favourably than non-Indigenous applicants' resumés.

Additionally, we sought to examine the effects of job type by comparing evaluations of applicants for a position within HR participants' own industry (HR Coordinator) and for a position outside of participants' own industry (CS assistant). We predicted that nonIndigenous HR professionals would rate and rank non-Indigenous applicants more favourably than Indigenous applicants for the HR (in-group) position and for fit with their own work team (TF); but rate and rank non-Indigenous and Indigenous applicants equally for the CS (out-group) position.

In line with research that has consistently reflected a bias against females, we sought to investigate whether female and male HR professionals' ratings and rankings of male and female applicants' resumés differ according to gender matching of evaluators and applicants. Finally, 
in response to evidence suggesting that forced ranks are more sensitive than ratings to subtle biases (Arvey, 1979; Ding \& Stillman, 2005; Gouvier et al., 2003; Marlowe et al., 1996), we sought to investigate whether participant attitudes and gender have a differential effect on male and female Indigenous and non-Indigenous applicants' resumé ratings and rankings.

\section{Method \\ Participants}

HR and recruitment professionals were selected because they play an integral part in real employment selection. A total of 130 professionals from the Sunshine Coast region of Queensland, Australia and from a national company were identified and invited to participate in the research. It was an agreed condition of participation that the company would not be named. Because responses were submitted anonymously online, it was impossible to identify the company or location in which respondents worked. In total, 60 replies (overall response rate of $46 \%$ ) were received. Of the 60 participants, 41 $(68.3 \%)$ were female and $19(31.7 \%)$ were male. The large majority of participants had at least two years' experience in the HR or recruitment industry, with 18 (30\%) having eight years' or more experience, 16 (26.7\%) having five to seven years' experience, 18 (30\%) having two to four years' experience, and 8 (13.3\%) having a year's experience or less. Forty-six (76.7\%) participants indicated that university was their highest level of education, compared with TAFE $(n=9,15 \%)$, Year 12 education $(n=4,6.7 \%)$, and Year 10 education $(n=1$, $1.7 \%)$. The majority ( $n=43,72 \%)$ were between $21-40$ years of age. All were non-Indigenous Australians.

\section{Materials}

Application forms. There were four resumés that were identical visually and contained the following sections: personal details, citizenship information, educational background, work history, computer skills and a declaration. The four fictitious applicants were assigned gender-neutral given names and family names that could either be for Indigenous or non-Indigenous Australian families (e.g., Ashley Pearson). Each applicant's gender and ethnicity was indicated by ticked boxes within the personal details section, as is frequently the case on employment application cover sheets. Four personal profiles were thus created for an Indigenous male, an Indigenous female, a non-Indigenous male and a non-Indigenous female. The remaining sections of the applications were similar in terms of citizenship (Australian citizen or permanent resident), educational background (a Bachelor of Business from an Australian university), work history (customer service, administrative and personnel experience), and computer skills (Microsoft Office ${ }^{\bowtie}$, Internet and in-house database). The personal details section (i.e., name, contact details, gender and ethnicity) was counterbalanced across the four applicant educational and work histories, generating four separate but similar versions of each Indigenous male, Indigenous female, non-Indigenous male and non-Indigenous female resumé. This method of counterbalancing applicants' gender and ethnicity with other background information ensured that any unanticipated differences between applicants' education, work history and computer skills would equally advantage or disadvantage each of the four gender $\mathrm{x}$ ethnicity personal profiles. Pilot testing of the resumés indicated that they were easily differentiated by applicants' gender and ethnicity but could not be separated on the basis of citizenship information, educational background, work history or computer skills.

Online questionnaire. The online questionnaire contained one section per web page. The first section required participants to rate each of the four resumés for a HR Coordinator's position on five separate key selection criteria (educational qualifications, employment history, potential to work effectively within a team, computer skills and potential to use initiative and work unsupervised; rating on each key criterion was on a 1-5 scale with high scores indicating a favourable match against the key criterion). Section 2 required participants to rank the applicants from 1 (Most suitable) to 4 (Least suitable) in order of suitability for the HR position, and then to rank the applicants from 1 to 4 as above in order of who would be most likely to fit in with their current HR team (TF). Section 3 required participants to rate the same four resumés for the role of CS assistant against each of the same key selection criteria above. Section 5 required them to rank applicants from 1 to 4 in order of suitability for the CS position. Section 6 requested participants' age, gender, ethnicity, education and years of experience.

Finally, section 7 contained a modified 12 -item version of Pedersen and colleagues' (2004) 18-item Attitude toward Indigenous Australians (ATIA) scale. The modified ATIA scale consisted of 12 items derived exclusively from Pedersen and colleagues' (2004) Factor 1, which measured general attitude towards Indigenous Australians. ATIA item scores were tallied to produce an overall score for each participant. The statement 'Aboriginal people work as hard as anyone else' was reverse-scored, so that a high overall score indicated a negative attitude towards Indigenous people. The 12item scale had an internal reliability $(\alpha)$ of .93, which is equal to the reported reliability of Pedersen and colleagues' (2004) original 18-item scale. Participants were categorised as holding either a negative or a positive attitude towards Indigenous Australians, with a negative attitude indicated by a score above the sample's mean scale score and a positive attitude indicated by a score below the sample's mean scale score. 


\section{Procedure}

Potential participants were identified by: searching for recruitment agencies in the Yellow Pages ${ }^{\mathrm{TM}}$ directory; locating HR managers' contact details on local company websites; contacting HR networking groups; and contacting a national company with a number of locally based HR teams.

Participants were invited individually by e-mail to participate in the research. The e-mail contained a brief statement requesting their participation, along with instructions regarding two e-mail attachments: an information statement; and a single file containing four resumés. All participants received the same e-mailed invitation and information statement, but were randomly allocated to receive one set of the four resumé variations. Participants were instructed to read the attached information statement. This document contained information about the study, consent, anonymity, use and storage of information, and a hyperlink to request a summary of the results (USC ethics clearance \#S/09/198). Participants were advised that the aim of the project was to study factors affecting hiring decisions so that they remained unaware that it aimed to investigate specifically the influence of applicants' ethnicity and gender, and participants' attitudes towards Indigenous people. Participants were instructed to print the attached resumés because they would need to refer to them when completing the online questionnaire.

The e-mail also contained a hyperlink to the online questionnaire. After downloading and reading the four resumés attached to the e-mail, participants activated the hyperlink in the e-mail and completed the online questionnaire consisting of seven sections. The questionnaire was designed in a way that required participants to answer all questions (there were no missing data) and to work sequentially through the sections. As they navigated forward through the sections, they were unable to navigate back to completed sections. Participants completed and submitted the online questionnaire anonymously. A first reminder notice was e-mailed to all participants two weeks after the initial email invitation, and a second reminder was e-mailed two weeks after the first reminder. Responses were downloaded from the questionnaire website in the form of an Excel $^{\circledast}$ spreadsheet that was imported into SPSS software for analysis.

\section{Results}

A general linear model (GLM) mixed model repeated measures multiple analysis of variance (MANOVA) was used to analyse resumé ratings. The between-groups variables were 2 (participant gender: male vs. female) $\times$ 2 (participant attitude: positive vs. negative); and the within-groups variables were 2 (applicant ethnicity: Indigenous vs. non-Indigenous) $\times 2$ (applicant gender: male vs. female $) \times 2$ (job type: $\mathrm{HR}$ vs. $\mathrm{CS}$ position). The dependent variables were the five separate suitability ratings (educational qualifications, work history, potential to work effectively within a team, computer skills and potential to use initiative and work unsupervised). A high rating was favourable, indicating a match to the key selection criteria. The only significant difference was for the overall main effect of job type, $F(5,52)=7.73, p$ $<.000$. Participants rated applicants' resumés more favourably overall for the CS $(M=4.16)$ than for the HR $(M=3.90)$ position. This difference was reliable separately for the dependent variables of educational qualifications, $F(1)=27.74, p<.000$, work history, $F(1)$ $=16.24, p<.000$, teamwork, $F(1)=5.21, p=.03$, and initiative, $F(1)=4.52, p=.03$, but not for computer skills, $F(1)=0.65$, ns. The main effect of applicant ethnicity overall on ratings was not significant; the main effect of participant attitude overall on ratings was not significant; the interaction effect of applicant ethnicity $\times$ job type overall was not significant; and the interaction effect of participant gender $\times$ applicant gender overall on ratings was not significant.

The Friedman test with Kendall's coefficient of concordance, followed by a Wilcoxon test controlling for Type 1 error using the Bonferroni method, was used to analyse differences between resumé rankings for the non-Indigenous male, non-Indigenous female, Indigenous male and Indigenous female applicants separately for the dependent variables of HR rank, TF rank and CS rank. Differences were analysed first of all for the whole sample $(N=60)$ and then for participants holding positive attitudes to Indigenous people $(N=$ 33), participants holding negative attitudes toward Indigenous people $(N=27)$, male participants $(N=19)$, and female participants $(N=41)$. The lower the rank, the more favourable were participants' evaluations of a resumé. The results are summarised in Table 1.

HR rank differences for the four applicants were significant $(p=.009)$. Wilcoxon paired comparisons showed that the non-Indigenous male $(M$ rank $=2.07)$ was ranked more favourably than the Indigenous male $(M$ rank $=2.85)(p=.002)$ and the Indigenous female $(M$ rank $=2.60)(p=.025)$. Participants holding negative attitudes assigned significantly different HR ranks to the four applicants $(p<.001)$. They ranked the nonIndigenous male $(M$ rank $=1.81)$ more favourably than the Indigenous male $(M$ rank $=3.22)(p<.001)$ and the Indigenous female $(M$ rank $=2.78)(p=.004)$; and the non-Indigenous female $(M$ rank $=2.19)$ more favourably than the Indigenous male $(p=.001)$. Female participants assigned significantly different HR ranks to the four applicants $(p=.016)$. Female participants ranked the non-Indigenous male $(M$ rank $=2.00)$ more favourably than the Indigenous male $(M$ rank $=2.90)(p$ $=.003)$ and the non-Indigenous female $(M$ rank $=2.59)$ $(p=.038)$. 
TF rank differences for the four applicants were significant $(p=.044)$. Wilcoxon paired comparisons showed that the non-Indigenous male $(M$ rank $=2.22)$ was ranked more favourably than the Indigenous male $(M$ rank $=2.85)$ $(p=.006)$. Participants holding negative attitudes assigned significantly different TF ranks to the four applicants $(p=$ $.002)$. They ranked the non-Indigenous male ( $M$ rank $=$ 2.11) more favourably than the Indigenous male $(M$ rank $=$ 3.15) $(p=.001)$ and the Indigenous female ( $M$ rank $=$ 2.78) $(p=.039)$; and the non-Indigenous female $(M$ rank $=$ 1.96) more favourably than the Indigenous male $(p=$ $.003)$. Female participants assigned significantly different TF ranks to the four applicants $(p=.013)$. Female participants ranked the non-Indigenous male $(M$ rank $=2.17)$ more favourably than the Indigenous male $(M$ rank $=3.02)$ $(p=.003)$; and they ranked and the non-Indigenous female $(M$ rank $=2.27)$ more favourably than the Indigenous male $(p=.027)$.

CS rank differences for the four applicants across the whole sample were not significant. However, participants holding negative attitudes assigned significantly different CS ranks to the four applicants $(p=.036)$. They ranked the non-Indigenous male $(M$ rank $=2.15)$ more favourably than the Indigenous male $(M$ rank $=3.04)(p=.005)$ and the non-Indigenous female $(M$ rank $=2.19)$ more favourably than the Indigenous male $(p=.015)$.

$\mathrm{HR}$, TF and CS ranks assigned to the four resumés did not differ significantly for participants holding positive attitudes toward Indigenous people or for male participants.

\section{Discussion}

Our predictions that non-Indigenous HR professionals would rate non-Indigenous applicants' resumés more favourably than Indigenous Australian applicants' resumés, that participants' attitudes toward Indigenous Australians would influence their ratings in favour of the non-Indigenous applicants over the Indigenous applicants, and that non-Indigenous applicants would be rated more favourably than Indigenous applicants for the HR position and TF, were not supported. The only reliable prediction about ratings was that there would not be a difference between the Indigenous and nonIndigenous resumé ratings overall for the CS position. This finding is consistent with explanations of recruitment decision-making based on social identity theory and job complexity.

The results offered support for our predictions that non-Indigenous applicants would be ranked more favourably than the Indigenous applicants for the HR Coordinator position (the non-Indigenous male was preferred to the Indigenous male and Indigenous female) and for current team fit (the non-Indigenous male was preferred to the Indigenous male). These results are consistent with overseas findings that ethnic majority research participants are more likely to prefer ethnic majority job applicants than ethnic minority applicants (Dovidio \& Gaertner; 2000; Hosoda et al., 2003; Purkiss et al., 2006; Singer \& Eder, 1989). They also offer implicit support for the proposition that discriminatory workplace practices may contribute to the high rate of Indigenous unemployment (Davidson, 1984).

Although applicants were ranked differently for the HR position and on current team fit, they were, as predicted, not ranked differently for the CS position, suggesting non-Indigenous HR professionals may be less discerning about applicants' ethnicity or gender when considering applicants for a position outside of their

\section{Table 1}

Friedman Test of Differences in Résumé Rankings

\begin{tabular}{|c|c|c|c|c|}
\hline Variable & $\chi^{2}$ & $(d f, N)$ & Kendall's W & Sig. \\
\hline \multicolumn{5}{|l|}{ HR rank } \\
\hline Whole sample & 11.54 & 3,60 & .06 & $p=.009$ \\
\hline $\mathrm{P}$ attitude +ve & 2.13 & 3,33 & .02 & ns \\
\hline P attitude -ve & 18.91 & 3,27 & .23 & $p<.001$ \\
\hline Male P & 1.86 & 3,19 & .03 & $n s$ \\
\hline Female P & 10.32 & 3,41 & .08 & $p=.016$ \\
\hline \multicolumn{5}{|l|}{ TF rank } \\
\hline Whole sample & 8.10 & 3,60 & .05 & $p=.044$ \\
\hline $\mathrm{P}$ attitude +ve & 1.98 & 3,33 & .02 & $n s$ \\
\hline P attitude -ve & 15.18 & 3,27 & .19 & $p=.002$ \\
\hline Male P & 0.66 & 3,19 & .01 & $n s$ \\
\hline Female P & 10.79 & 3,41 & .09 & $p=.013$ \\
\hline \multicolumn{5}{|l|}{ CS rank } \\
\hline Whole sample & 3.52 & 3,60 & .02 & ns \\
\hline$P$ attitude +ve & 1.62 & 3,33 & .02 & ns \\
\hline $\mathrm{P}$ attitude -ve & 8.56 & 3,27 & .11 & $p=.036$ \\
\hline Male P & 1.67 & 3,19 & .03 & ns \\
\hline Female $\mathrm{P}$ & 3.47 & 3,41 & .03 & ns \\
\hline
\end{tabular}

Note: $\mathrm{P}$ attitude $+\mathrm{ve}=$ Participants holding positive attitudes toward Indigenous people; $\mathrm{P}$ attitude $-\mathrm{ve}=$ Participants holding negative attitudes toward Indigenous people; Male $\mathrm{P}=\mathrm{Male}$ participants; Female $P=$ Female participants 
industry than for a position within their own industry. These rank discrepancies are consistent with a social identity theory of discrimination, whereby in-group applicants are likely to be preferred over out-group applicants for in-group jobs (e.g., Dovidio \& Gaertner, 2000). However, the result is also consistent with overseas findings that disadvantage for ethnic minority applicants is relatively greater for perceived high cognitive demand than perceived low cognitive demand jobs (Hosoda et al., 2003). Some support for the latter interpretation of the discrepancy between how the Indigenous applicants were ranked for the HR and CS positions is offered by the analysis of ratings: the significant main effect of job type on resumé ratings suggests that participants seemingly judged the CS position to be less demanding than the HR position on four of the five separate key selection criteria.

Ranks for non-Indigenous and Indigenous applicants, as predicted, were dependant on participants' attitude towards Indigenous Australians. When HR professionals held a positive attitude toward Indigenous Australians, their ranking of non-Indigenous and Indigenous applicants on the three dependent variables of HR, TF and CS rank did not differ significantly. However, participants holding a negative attitude towards Indigenous Australians ranked the resumés differently for the HR position, team fit, and the CS position; and they consistently preferred the nonIndigenous male applicant to the Indigenous male and female applicants, and the non-Indigenous female applicant to the Indigenous male applicant. These results are congruent with suggestions by Donovan and Leivers (1993) and Tickner (1994) that non-Indigenous Australians may hold perjorative beliefs about Indigenous people's attitudes to, and engagement with, work. They also have serious implications for Indigenous people being able to find work, considering that prejudice against Indigenous people among nonIndigenous Australians is widespread (Pedersen \& Walker, 1997; Pedersen et al., 2000; Pedersen et al., 2004; Pedersen et al., 2006).

The discrepancy between decision-makers' resumé ratings and ranks suggests that modern or subtle prejudice instead of old-fashioned or blatant prejudice (Gaertner \& Dovidio, 2005) may influence evaluations of Indigenous Australian applicants. It also supports previous findings that resumé ranks may be more sensitive than resumé ratings to biases in decision-makers' attributes and attitudes (Arvey, 1979). Indigenous and non-Indigenous applicants may be - and were - rated similarly based on their background and experience against key selection; however, Indigenous applicants may be - and were - ranked less favourably than nonIndigenous applicants. Such a discrepancy between ratings and ranks has significant implications for 'real' hiring decisions because there is generally a list of appli- cants for any position and only those who are ranked most favourably at the short-listing stage are likely to be invited for interview. Indigenous applicants may be excluded at the interview stage because they are ranked less favourably than similarly qualified and experienced non-Indigenous applicants, despite being rated similarly to the latter applicants on key selection criteria.

These findings have implications for professional practice as well as for future research. Contemporary recruitment and selection processes, despite the veneer of objectivity afforded by quantitative ratings and rank ordering, are not necessarily bias-free, which raises questions about equity. If Indigenous applicants rate as well on key selection criteria as non-Indigenous applicants, they deserve a chance at interview to demonstrate their suitability for the position. Professional development aimed at assisting recruiters to understand the subtle biases that are inherent in contemporary recruitment processes, which rely on quantitative rating and ranking of job applicants, should be available and encouraged. In addition, the value for fairness and equity in recruitment decision-making of HR professionals holding a positive attitude toward Indigenous Australians is strongly supported by our findings. Personal and professional development opportunities that challenge HR and recruitment professionals' false beliefs about, and prejudices against, Indigenous Australians should be available through relevant professional associations and networks. This includes addressing false beliefs about Indigenous applicants being more suitable for low cognitive demand than high cognitive demand positions even when they possess the skills required for the latter positions, reflecting on the possibilities and challenges associated with membership of socially and culturally diverse workplace teams and professional grouping, and recognition of the fact that work colleagues do not need to be 'like us' socially and culturally in order to perform their duties effectively and contribute productively to the team. However, it is important to acknowledge that changing people's negative attitudes and false beliefs about Indigenous people is not necessarily easily achieved and that specific strategies for education and training are required for increasing professionals' cultural competence (Davidson, 1999; Pedersen \& Barlow, 2008; Pedersen, Walker, \& Wise, 2005).

Female participants' preferred choice of the nonIndigenous male applicant over the Indigenous male and female applicants on the in-group HR and TF ranks was unexpected and it is not easily explained. Ex post facto analysis of male and female participants' scores on the modified ATIA scale indicated that there was no relationship between gender and assignment to the positive or negative attitude group, $\chi^{2}(d f 1)=0.06, n s$, and there were no overall scale score differences for males and females, $t=0.26$ ( $d f 58)$, ns. On the contrary, Pedersen and Walker (1997) found that males scored more highly 
than females on measures of old-fashioned and modern prejudice. Given that a considerable proportion of HR professionals are female, this finding needs replication and further investigation.

Contrary to expectation, there was no evidence that male and female professionals favoured applicants of like gender (e.g., female participants did not prefer the female applicants to the male applicants) and, contrary to overseas findings, the male applicants were not rated or ranked consistently more favourably than the female applicants. It is suggested that these discrepant findings relating to effects of gender on recruitment in general and on Indigenous male and female employment rates (ABS, 2007, 2008) also require further investigation. In particular, in the same way that the present investigation examined the interactive effects of applicant ethnicity and attitudes toward Indigenous Australians on resumé evaluation, future research may examine the differential effects of decision-maker-applicant gender matching and decision-makers' gender attitude on resumé evaluation. Inclusion in future research of Hofstede's (1984) concept of masculinity, or a measure of gender attitude (Ashmore, Del Boca, \& Bilder, 1995), or of gender role attitude (McHugh \& Frieze, 1997; Spence \& Hahn, 1997) may address this attitudinal dimension of recruitment decision-making.

The study has a number of possible limitations. It is not necessarily common practice to make hiring decisions based only on resumé evaluations. HR professionals generally use a number of selection techniques including interviews, practical tests, and reference checks to aid decision-making. The findings, therefore, should be tempered by the fact that HR professionals who participated were required to make judgments without speaking to or seeing applicants. However, we argue that a common first step in selection is to create an applicant shortlist using ratings and ranking based on information contained in job resumés before the interview stage of the selection process begins. Therefore, if recruiters' decisions are influenced by stereotypes of, and prejudices against, applicants from particular ethnic backgrounds those applicants are likely to be excluded from further consideration at the short-listing stage. The biggest challenge for suitably qualified Indigenous job applicants may be making it to the interview stage, especially if the decision-maker is negatively disposed towards Indigenous people generally. Consequently, they will not have the opportunity to attend an interview to impress employers with their knowledge and skills.

The current findings are based on the responses of $60 \mathrm{HR}$ and recruitment professionals from the Sunshine Coast, Australia, and from a national company. The method of anonymous data collection meant it was impossible to distinguish between participants from local Sunshine Coast businesses and those from the large national organisation, or to distinguish participants by industry. To understand the difficulties encountered by Indigenous job seekers better, we recommend that both regional and industry-specific attitudes and recruitment approaches to Indigenous people be further investigated.

Finally, there was no difference between Indigenous and non-Indigenous applicants' ranks for the CS position. However, the present study did not permit separate examination of social identity (e.g., Gaertner \& Dovidio, 2005) and cognitive demand (e.g., Hosoda et al., 2003) explanations of this finding. Future research with a larger sample may be able to segment the effects of group identity and cognitive demand by broadening the number of employment positions to include more junior (low demand) and more senior (high demand) same-industry (in-group) and different-industry (outgroup) positions.

\section{Author Note}

The research was completed in late 2009 when both authors were affiliated with the School of Social Sciences, University of the Sunshine Coast, Australia.

\section{References}

Arvey, R.D. (1979). Unfair discrimination in the employment interview: Legal and psychological aspects. Psychological Bulletin, 86(4), 736-765.

Ashmore, R.D., Del Boca, F.K., \& Bilder, S.M. (1995). Construction and validation of the Gender Attitude Inventory, a structured inventory to assess multiple dimmensions of gender attitudes. Sex Roles, 32(11-12), 753-785.

Augoustinos, M., Tuffin, K., \& Sale, L. (1999). Race talk. Australian Journal of Psychology, 51(2), 90-97.

Australian Bureau of Statistics. (2007). Labour force characteristics of Aboriginal and Torres Strait Islander Australians: Experimental estimates from the labour force survey (Cat. no. 6287.0). Retrieved March 28, 2009, from http://www. ausstats. abs.gov.au/ausstats/subscriber.nsf/0/F6AE80CEC4FD6F5FCA 257450001581EB/\$File/62870_2007.pdf

Australian Bureau of Statistics. (2008). Labour statistics in brief (Cat. no. 6104.0). Retrieved March 28, 2009, from http://www.ausstats.abs.gov.au/ausstats/subscriber.nsf/0/DD2 7AA795D22E49FCA25744F00151D8D/\$File/61040_2008.pdf Australian Government. (1975). Racial Discrimination Act. Canberra, Australia: Attorney General's Department.

Australian Government. (1984). Sex Discrimination Act. Canberra, Australia: Attorney General's Department.

Australian Government. (2004). Age Discrimination Act. Canberra, Australia: Attorney General's Department.

Blascovich, J., Wyer, N.A., Swart, L.A., \& Kibler, J.L. (1997). Racism and racial categorisation. Journal of Personality and Social Psychology, 72(6), 1364-1372.

Booth, A., Leigh, A., \& Varganova, E. (2009). Does racial and ethnic discrimination vary across minority groups? Evidence from three experiments. Retrieved August 6, 2009, from http:// econrsss.anu.edu.au/ aleigh/pdf/AuditDiscrimination.pdf

Davidson, G. (1984). Australian Aboriginal unemployment: Is it a case of psychological readiness or racism? ERIC Clearing House on Urban Education (Colombia University) Resources in Education, April, (ERIC Document Reproduction Service No. ED 237 587). 
Davidson, G.R. (1999). Cultural competence as an ethical precept in psychology. In P. Martin \& W. Noble (Eds.), Psychology and society (pp. 162-174). Brisbane, Australia: Australian Academic Press.

Ding, V.J., \& Stillman, J.A. (2005). An empirical investigation of discrimination against overweight female job applicants in New Zealand. New Zealand Journal of Psychology, 34(3), 139-148.

Dipboye, R.L., Arvey, R.D., \& Terpstra, D.E. (1977). Sex and physical attractiveness of raters and applicants as determinants of resumé evaluations. Journal of Applied Psychology, 62(3), 288-294.

Dipboye, R.L., Fromkin, H.L., \& Wilback, K. (1975). Relative importance of applicant sex, attractiveness, and scholastic standing in evaluation of job applicant resumés. Journal of Applied Psychology, 60(1), 39-43.

Donovan, R.J., \& Leivers, S. (1993). Using paid advertising to modify racial stereotype beliefs. Public Opinion Quarterly, 57(2), 205-218.

Dovidio, J.F., \& Gaertner, S.L. (2000). Aversive racism and selection decisions: 1989 and 1999. Psychological Science, 11(4), 315-319.

Feather, N.T., \& O'Brien, G.E. (1986). A longitudinal study of the effects of employment and unemployment on school leavers. Journal of Occupational Psychology, 59(2), 121-144.

Gaertner, S.L., \& Dovidio, J.F. (2005). Understanding and addressing contemporary racism: From aversive racism to the common ingroup identity model. Journal of Social Issues, 61(3), 615-639.

Gomersall, A.M., Davidson, G., \& Ho, R. (2000). Factors affecting acceptance of Aboriginal reconciliation amongst nonIndigenous Australians. Australian Psychologist, 35(2), 118-127.

Gordon, M.E., Slade, L.A., \& Schmitt, N. (1986). The 'science of the sophomore' revisited: From conjecture to empiricism. Academy of Management Review, 11(1), 191-207.

Gorman, E.H. (2005). Gender stereotypes, same-gender preferences, and organizational variation in the hiring of women: Evidence from law firms. American Sociological Review, 70(4), 702-728.

Gouvier, W.D., Sytsma-Jordan, S., \& Mayville, S. (2003). Patterns of discrimination in hiring job applicants with disabilities: The role of disability type, job complexity, and public contact. Rehabilitation Psychology, 48(3), 175-181.

Gringart, E., Helmes, E., \& Speelman, C. (2008). Harnessing cognitive dissonance to promote positive attitudes toward older workers in Australia. Journal of Applied Social Psychology, 38(3), 751-778.

Hoban, R. (2002). Mental health promotion and work: Rumbalara community's roundtable discussion 2002. In L. Morrow, I. Verins, \& E. Willis (Eds.), Mental health and work: Issues and perspectives (pp. 63-73). Adelaide, Australia: The Australian Network for Promotion, Prevention and Early Intervention for Mental Health.

Hofstede, G. (1984). Culture's consequences: International differences in work-related values. Beverly Hills, CA: Sage.

Hosoda, M., Stone, D.L., \& Stone-Romero, E.F. (2003). The interactive effects of race, gender, and job type on job suitability ratings and selection decisions. Journal of Applied Social Psychology, 33(1), 145-178.

Levin, I.P., Rouwenhorst, R.M., \& Trisko, H.M. (2005). Separating gender biases in screening and selecting candidates for hiring and firing. Social Behavior and Personality, 33(8), 793-804.
McHugh, M.C., \& Frieze, I.H. (1997). The measurement of gender-role attitudes: A review and commentary. Psychology of Women Quarterly, 21(1), 1-16.

Marlowe, C.M., Schneider, S.L., \& Nelson, C.E. (1996). Gender and attractiveness biases in hiring decisions: Are more experienced managers less biased? Journal of Applied Psychology, 81(1), 11-21.

Masser, B., Grass, K., \& Nesic, M. (2007). We like you, but we don't want you: The impact of pregnancy in the workplace. Sex Roles, 56(9), 703-712.

Pedersen, A., \& Barlow, F.K. (2008). Theory to social action: A university-based strategy targeting prejudice against Aboriginal Australians. Australian Psychologist, 43(3), 148-159.

Pedersen, A., Beven, J., Walker, I., \& Griffiths, B. (2004). Attitudes toward Indigenous Australians: The role of empathy and guilt. Journal of Community and Applied Social Psychology, 14(4), 233-249.

Pedersen, A., Dudgeon, P., Watt, S., \& Griffiths, B. (2006). Attitudes toward Indigenous Australians: The issue of 'special treatment'. Australian Psychologist, 41(2), 85-94.

Pedersen, A., Griffiths, B., Contos, N., Bishop, B., \& Walker, I. (2000). Attitudes toward Aboriginal Australians in city and country settings. Australian Psychologist, 35(2), 109-117.

Pedersen, A., \& Walker, I. (1997). Prejudice against Australian Aborigines: Old-fashioned and modern forms. European Journal of Social Psychology, 27(5), 561-587.

Pedersen, A., Walker, I., \& Wise, M. (2005). 'Talk does not cook rice': Beyond anti-racism rhetoric to strategies for social action. Australian Psychologist, 40(1), 20-30.

Podsiadlowski, A., \& Ward, C. (2010). Global mobility and bias in the workplace. In S.C. Carr (Ed.), The psychology of global mobility (pp. 279-300). New York: Springer.

Purkiss, S.L., Perrewé, P.L., Gillespie, T.L., Mayes, B.T., \& Ferris, G.R. (2006). Implicit sources of bias in employment interview judgements and decisions. Organizational Behavior and Human Decision Processes, 101(2), 152-167.

Sibley, C.G., \& Liu, J.H. (2004). Attitudes towards biculturalism in New Zealand: Social dominance and Pakeha attitudes towards the general principles and resource-specific aspects of bicultural policy. New Zealand Journal of Psychology, 33(2), 88-99.

Sibley, C.G., Liu, J.H., \& Kahn, S.S. (2008). Who are 'we'? Implicit associations between ethnic and national symbols for Maori and Pakeha in New Zealand. New Zealand Journal of Psychology, 37(2), 38-49.

Singer, M. (1988). The effect of applicant ethnicity on selection decisions: Are results generalisable from resumé to interview research? Australian Journal of Psychology, 40(4), 423-431.

Singer, M. (1996). Effects of scope of justice, informant ethnicity, and information frame on attitudes towards ethnicity-based assessment. International Journal of Psychology, 31(5), 191-205.

Singer, M., \& Eder, G.S. (1989). Effects of ethnicity, accent, and job status on selection decisions. International Journal of Psychology, 24(1), 13-34.

Singer, M., \& Sewell, C. (1989). Applicant age and selection interview decisions: Effect of information exposure on age discrimination in personnel selection. Personnel Psychology, 42(1), 135-154.

Spence, J.T., \& Hahn, E.D. (1997). The Attitudes Toward Women Scale and attitude to change in college students. Psychology of Women Quarterly, 21(1), 17-34. 
Stokes, G. (1991). Work, unemployment and mental health. In R. Cochrane \& D. Carroll (Eds.), Psychology and social issues: A tutorial text (pp. 140-149). London: Falmer Press.

Tajfel, H., \& Forgas, J.P. (2000). Social categorisation: Cognitions, values and groups. In C. Stangor (Ed.), Stereotypes and prejudice (pp. 49-63). Philadelphia: Psychology Press.

Tajfel, H., \& Turner, J.C. (2004). The social identity theory of intergroup behaviour. In J.T. Jost \& J. Sidanius (Eds.), Political psychology: Key readings in social psychology (pp. 276-293). New York: Psychology Press.
Tickner, R. (1994). Rebutting the myths: Some facts about Aboriginal and Torres Strait Islander Affairs. Retrieved March 28, 2009, from Australasian Legal Information Institute website: http://www.austlii.edu.au/au/other/IndigLRes/1994 /1/index.html

Warr, P. (1978). A study of psychological well-being. British Journal of Psychology, 69(1), 111-121.

Winefield, A.H., Montgomery, B., Gault, U., Muller, J., O’Gorman, J., Reser, J., et al. (2002). The psychology of work and unemployment in Australia today: An Australian Psychological Society discussion paper. Australian Psychologist, 37(1), 1-9. 